\title{
Interrogation on "Go across the Street in Chinese-Style" -Analysis from the Game Perspective of the Officials and the Public
}

\author{
Yuan $\mathrm{He}^{1}$ \\ ${ }^{1}$ China Political Science University, Beijing, 100088 \\ 346591653@163.com
}

KEYWORDS: Game of the Officials and the Public; Enforcement Costs; Spontaneous Order

\begin{abstract}
Pedestrian traffic violations through acts of self-regulation seems to exist from the endless stretches on and become a law enforcement traffic control problems, "Chinese-style across the street" is one specific case, investigate the case may provide inspiration to deal with related issues. Based on the analysis, "Chinese-style across the street," starting to discuss the enforcement of traffic control problems and trying to find a better solution to address these issues.
\end{abstract}

\section{Introduction}

"Lobbied handful of people can go, and the traffic lights do not care" - currently this is called "Chinese-style across the street," the phenomenon is the traffic regulation a hard nut to crack, to take measures to curb the country, "Chinese-style across the street." , but has not yet reached the desired results. Futile or less effective in the satirical comedy is a joke, but in their own and related costs and devote the reality is difficult to produce comic effect, punish "Chinese-style across the street," Why is this so? In the field of law, rules and existing research from two levels to expand law enforcement, the rule level, a survey of pedestrians crossing the road. 1, the lack of public awareness of the rules; 2, in the public road transport on the "freedom" to generate misunderstanding; 3 , right of way rules of the road, as defined in the presence of the unreasonable distribution. At the same time, a lot of the view that the failure to implement the relevant rules and regulations, and public institutions are responsible to deal with the relevant provisions, and then put the focus law enforcement level, scholars believe that pedestrian violations had low-risk road behavior and violation of the act and the low costs associated with so that even in the management of input costs will insist. Although the above discussion is different, but all maintained the "Chinese-style across the street" at arm's length attitude, and propose solutions. Seen and heard, I also "Chinese-style across the street" to produce research interests, from the analysis below will try to "Chinese-style across the street", discusses the related issues.

From the above, we use a certain amount of economic analysis to illustrate problems in the implementation of the law, while introducing the practice of information from the perspective of sociology of law, and inevitably with a little knowledge of psychology assisted analysis, but always focus on legal paper problem.

Basic point of this article is: 1, "Chinese-style across the street" is the pedestrian traffic on its own self-interest as a program object taken, there is competition between it and the traffic laws; 2 , the cost of enforcement of traffic laws hindered the implementation of such current the presence of law enforcement a lot of problems to the rule of law in a negative impact; 3 , the official 
rule-making should take into account public acceptance, respect the public spontaneous order. Based on the above point of view, the paper said: will focus on "Chinese-style across the street," the law enforcement officials and the public away from the game to level the legislative level can provide a solution to this problem, the need to develop the rule of law be respected public habits.

\section{The Analysis of “ Go across the Street in Chinese-Style”}

"Chinese-style across the street" is the 2012 "invention" to illustrate an argument pedestrian crossing the street pushing into illegal behavior, in my view, which gives two messages: 1 . It is mainly for pedestrians, two such violations behavior is labeled "Chinese-style" label. China's relevant laws and regulations, pedestrians crossing the road and following the corresponding traffic rules, pedestrians violating traffic lights and pushing into the traffic control signal or instructed to cross the road in violation of the relevant laws and regulations. The view on a phenomenon labeled "Chinese-style" tag challenged pedestrians crossing the road is not our only illegal thing.

\section{A. Distribution Right of Way}

Some scholars for the "Chinese-style across the street," the statement proposed allocation of rights of way is unreasonable, specifically in the red and green lights to meet the needs of the motor vehicle while exercising too little time left for pedestrians, sidewalks and other vehicles occupied or destroyed. In this paper, these data and examples to acknowledge, but in addition, requires a combination of right-of-assignment of the legal provisions: with international practice as pedestrian protection, our law is clear the right of way of pedestrians in road traffic regulations, and the right to life above the right of way - pedestrian negligence does not relieve or mitigate duty motor vehicle drivers. So look, but doubt exists unreasonable to say above the right of way assignment.

This paper argues that, in fact, another point of understanding "irrational distribution of right of way" is not in contradiction: on the one hand, the right of way of pedestrians rely on traffic lights, road marking and other technical measures, with technical properties, technical measures affecting the practice of right of way, such as traffic lights junction traffic lights time to meet the needs of the motor vehicle to exercise but did not meet the needs of pedestrians, technical operations squeeze pedestrians the right of way practice space.

On the other hand, the basis of allocation of rights of way is a right of passage, namely the right to use the main road resources implied condition is the existence of this right can be funded using the road, right of passage traced to the problem, along with the concept of road congestion such a situation - to solve the problem of scarce public resources, right-of-way means qualifications body use of resources. Road supply affect the rights, China's urban population, often leads to increase in the number of motor vehicles under the existing conditions of infrastructure cannot be synchronized in such a case, even if the law on the allocation of rights of way and then how to rely heavily on one side, the road up to a certain relative shortage the extent of any party concerned, will have serious distribution "uneven" because you want to protect the quality of road traffic will have an impact on the main right of way, such as the vehicle in accordance with the grade limit line to ease traffic congestion. Moreover, the protection of right of way road planning also have an impact, some small tunnels and across the street flyover flow of people, a lot of people and some intersection without a corresponding security facilities across the street, according to my observation, large flow of people, except near the zebra crossing without pedestrian tunnels and other facilities across the street, where once the red and green lights fail. The allocation of rights of way should be the method to solve the scarcity of public resources, but in excessive resource shortage failure is inevitable. 


\section{B. Impunity Public}

As pointed out above "unreasonable" it is the right way now assigned evaluations, subjective, subjectivity also has a "Chinese-style across the street," hold the psychology. In our history, official civil behavior approach, which social reasons behind the complex. The idea that now, it is one with legal management of urban failure. At different angles, can do different understanding. For the "Chinese-style across the street" in the law is not responsible for the public understanding of this paper is: in the course of road traffic, pedestrians individual rationality and collective psychological effects of the agreement.

As a stakeholder, pedestrian behavior on the road always have to take into account their prevailing interests. Although advocates of social comity during traffic regulation, the polite but does not hide its problems: road traffic in the main road traffic are hoping to enjoy the benefits of passage as possible. Although the law of balance between the main interests were defined, but cannot actually alleviate the conflict of interests between, on the one hand, as analyzed above, the allocation of rights of way in practice because the technology does, urban planning and infrastructure construction and other reasons exist unreasonable, and even the passage of a serious loss of body to produce a sense of interest; on the other hand, the use of the road, due to its nature with quasi-public goods, the main parties in the use of a particular space on the road there must be a conflict of interest. Even with traffic regulations, public transport facilities cannot suppress the "profit center" and make behavioral choices based on their interests whether this choice for compliance regulations.

Thus it is seen, whether it is to assign the right way unreasonable, pushing his hands are behind the interests of pedestrian traffic, "Chinese-style across the street" pedestrian behavior to take for their own self-interests masquerade traffic regulations in miniature. Self pedestrian behavior is not to be willing to recognize the existing traffic laws on "Chinese-style across the street" to rectify this is actually curb pedestrian disorder, potentially dangerous self behavior. With the implementation of traffic laws, the law enforcement level based on the right of way, "the official People Game" appears: on the road impassable, official programs to provide access based on the rule of law, and as a guarantee of power and the "Chinese-style across the street" Where traffic enforcement can be regarded as the official means of support, but the problem is that this means can improve the competitiveness of the official program it? This paper argues that, as a national force of expression, for the "Chinese-style across the street" traffic enforcement may have some significance, but not as an official program to provide enough chips to compete with the private sector. Traffic Enforcement Discussion below, explore why it cannot meet the needs of the official program of the game.

\section{The Crux of the Traffic Enforcement}

\section{A. Enforcement Costs}

From a law enforcement cost analysis, "Chinese-style across the street" This universality illegal punishment, hard to imagine the huge cost of inputs, measures of concentration and control from some of the city visible, even in economically developed areas, for investment in traffic enforcement the cost is not entirely "in place", which makes selective traffic enforcement cannot avoid becoming a campaign-style law enforcement and law enforcement.

With practice, it can be relatively selective traffic enforcement and law enforcement sites seen from law enforcement. The existing fines, for example, at the intersection of uncertain factors occasional pedestrian supervision and penalties, requires a certain amount of manpower, otherwise it is difficult to ensure the fair treatment of illegal body, but the actual process of law enforcement, 
affect the passage of too much traffic, it may not be equally subject to the law. At the same time, it is impossible to protect every intersection has a traffic enforcement, enforcement of pedestrian crossing locations based on violations of the law, to determine the intersection congestion, etc., which caused some of the probability of the intersection "Chinese-style across the street" phenomenon is very small or even zero penalties, even in the country can be seen in all regions of the "Chinese-style across the street," the law enforcement are not the same, for example, when a pedestrian claiming violations of Zhejiang fined not be punished in other areas of law enforcement to express dissatisfaction.

Traffic enforcement for universal phenomenon because while the performance of campaign-style law enforcement in practice have been concerned about academics, in addition to the gravity of the offense this reason, the root cause lies in the same limited enforcement costs. Compared to the long-term law enforcement, campaign-style law enforcement management resource requirements low, the "centralized regulation", "special" enforcement approach to mobilize limited resources in the short term to get a brief effect, limited in cost, the motion Enforcing law violations would be a means of treatment. But campaign-style law enforcement to make the public lose confidence in the rule of law, prejudice legal authority. Pay the enforcement costs of legal effect cannot be achieved.

\section{B. Rational Choice Pedestrians}

In the "Chinese-style across the street," the regulation, the implementation of the traffic regulations does not guarantee the legal effect of its implementation, the legal default build traffic order, even if the guarantee scheme by traffic enforcement official, the official program and the "Chinese-style across the street" is also the long-term coexistence with each other contest, which state: two programs exist interests coincide, but acts as an independent non-institutional living space occupied by the program in the community, although the law has the power to protect the program was inadequate. Acts not enough on their own law, the law enforcement is one of the reasons for the "Chinese-style across the street," the problem of aphasia, but limited to the cost of law enforcement, it is difficult to solve the problem at the level of law enforcement.

\section{One Possible Solution}

First, the spontaneous order and indicate the possible presence of road traffic order phase coexist order. Order refers to a form of the existence of things and behavior in road traffic, the traffic order is merely a form of an official to positive law perspective, with its rational construction colors. Traffic order and coexistence there are other road order, for example, in the performance of official duties did not see a police car driving in a motor vehicle during the initiative to give way, or pass process is seen in front of the elderly through specially detour. Spontaneous order is the construction of social order and the order of coexistence. There is competition between road coexistence order to establish and maintain traffic order traffic laws cannot ignore this.

Second, spontaneous is in order to establish the significance of traffic order for the smaller cost. Hayek's theory of legal rules on English common law background, and scholars believe that the rules of civil law countries compared to more common efficiency: First, from a legal background, civil law countries stressed that the implementation of policies, common law countries stressed market support ; secondly, from the source to see the rule of law, civil law rules of national law is "to develop" out, legally centrism color, in the implementation process dependent on external regulation, rule of law and common law countries is in practice "found "in the context of Hayek it is in the" social evolution gradually self "exists in the present social customs, practices, and a bottom-up process, and less dependent on external regulation, legal resources conservation; again, 
on specific issues, the rule of law as a statutory civil law countries, rely on force in the shortest possible period of time to establish a wide range of specific codes of conduct, but due to the limited rationality of legislators, law enforcement could not have foreseen the chain the reaction, so that the effect of legal resources outputs discounts, the rule of law in common law countries do not have this problem.

\section{Conclusion}

From the above analysis of "Chinese-style across the street," the visible, the high cost of enforcement of traffic laws is not to be effective and thus is an important reason to establish order in public transport, in the limited legal resources, programs, and public official traffic habits between the need for interaction, so that worked out of traffic regulations can be accepted by the public, the establishment of traffic order. Further seen an official game when people move from the level of law enforcement to the level of legal rules, the game between the desired result and the official program of the public is accustomed to effective traffic laws. To produce such an ideal outcome of the game, you may need to create a government and the people at the political level "talks" environment, but also requires a combination of regional disparities stimulate the enthusiasm of local authorities in the relevant matters, this article does not alone make, needs further study. Of course, the practice of non-fighting measure, which often inspire more solutions proposed rule of law prevailing habits of respect to the public is just one of the legal level to solve the "Chinese-style crossing the road" approach.

\section{REFERENCE:}

[1]Lim Ying Ting: "pedestrian red light running around the regulation cited concern, Qi Cheng called 'Chinese-style social rules across the street exposed anomie"', in "Legal Daily" 4th edition March 27, 2007.

[2]Jiluo Hong: "Strengthening the rule of law rules of social awareness, promote social management legalization", contained "Chinese law" 2012 the sixth period.

[3]Wang Wenchang: " 'Chinese-style disorder', the core is a misreading of freedom", in "Democracy and science" 2012 the sixth period.

[4]Li Fuyong: "Why tend to assign right of way Chinese motor vehicle", in "China Business Times" November 1, 2012 edition.

[5]Ye Quan: "-style look across the street from China to obey the law", in "Legal Daily" 7th Edition April 16, 2013.

[6]Chai Chun-yuan: "Radical 'Chinese-style across the street' Difficulties?", Contained "procuratorial daily" 4th edition December 3, 2012.

[7]Lige Jiang: " 'way -' and the 'right of way': 'right of way' connotation Legal Thinking", in "frontier" 201224.

[8]Li Fuyong: "Why tend to assign right of way Chinese motor vehicle", in "China Business Times" November 1, 2012 edition. 